\title{
MEDUNI WIEN TRAUERT UM BRUNO BAUER - LANGJÄHRIGER LEITER DER UNIVERSITÄTSBIBLIOTHEK UNERWARTET VERSTORBEN
}

von Karin Cepicka*

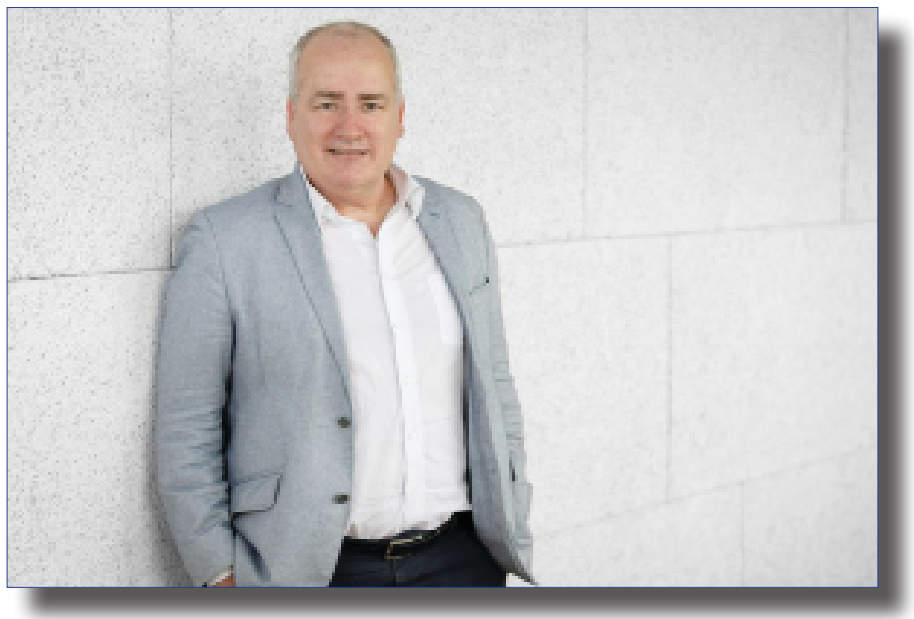

Abb. 1: Bruno Bauer (Foto: derKnopfdrücker)

Wir trauern um unseren lieben und sehr geschätzten Kollegen und Vorgesetzten, Mag. Bruno Bauer, den langjährigen Leiter der Universitätsbibliothek, der am 1. Dezember 2020 völlig unerwartet von uns gegangen ist.

Sein Tod hinterlässt in der deutschsprachigen Bibliothekslandschaft eine sehr große Lücke. Als Präsident der Vereinigung Österreichischer Bibliothekarinnen und Bibliothekare war er maßgeblich an der Entwicklung des österreichischen Bibliothekswesens beteiligt. Durch seine Vortragstätigkeit in der universitären Bibliotheksausbildung gab er sein großes Wissen vielen Generationen von Bibliothekarinnen und Bibliothekaren weiter. Im Bereich Open Access wurde seine umfassende Expertise weit über die MedUni Wien hinaus anerkannt. Weiters trug er als Pionier auf dem Gebiet e-only wesentlich zur Transformation vom gedruckten zum elektronischen Bibliotheksangebot bei.

Er war ein kluger Kopf, strukturierter Denker, großer Diplomat und Stratege, stets visionär, innovativ, zukunftsorientiert. 
Wir verlieren mit Bruno Bauer einen verständnisvollen, auf Kollegialität und das Wohl der Mitarbeiterinnen und Mitarbeiter bedachten Chef. Das ausgezeichnete Betriebsklima ist nicht zuletzt seiner umsichtigen, von Achtung und Respekt getragenen Führung zu verdanken.

Im Namen des gesamten Teams der Universitätsbibliothek...

$$
\begin{array}{r}
\text { Mag. }{ }^{a} \text { Karin Cepicka } \\
\text { Medizinische Universität Wien, Universitätsbibliothek } \\
\text { E-Mail: karin.cepicka@meduniwien.ac.at }
\end{array}
$$

* Der vorliegende Beitrag wurde erstmalig am 2. Dezember 2020 auf der Website der Medizinischen Universität Wien veröffentlicht (https:// www.meduniwien.ac.at/web/ueber-uns/news/detailseite/2020/newsim-dezember-2020/meduni-wien-trauert-um-bruno-bauer/).

DOI: https://doi.org/10.31263/voebm.v73i3-4.5270

(C) Karin Cepicka

Dieses Werk ist - exkl. einzelner Logos und Abbildungen - lizenziert unter einer Creative-Commons-Lizenz Namensnennung 4.0 International-Lizenz 